\title{
EDUCAÇÃO PERMANENTE: DIREITO DE CIDADANIA, RESPONSABILIDADE DO ESTADO
}

\author{
PERMANENT EDUCATION: CITIZENSHIP RIGHT, STATE RESPONSIBILITY
}

Carmen Sylvia Vidigal Moraes 1

Resumo Com o objetivo de manter interlocução com as formulações de Adriana Geisler, que analisam o significado da cidadania no Brasil hoje e propõem "identificar a que conceito de cidadania a noção de politecnia se filia", o texto procura contribuir para a contextualização do debate na realidade social brasileira, apresentando algumas reflexões sobre a forma assumida pelos direitos sociais e a condução das políticas governamentais no sentido de firmar sua universalidade no país. Neste percurso, discorre, em primeiro lugar, sobre o significado da educação permanente como direito social coletivo, e, em seguida, analisa, a partir das transformações na natureza e atuação do Estado nos anos 1990, as mudanças na configuração dos direitos sociais e das políticas públicas de educação e trabalho. Por fim, retoma-se a discussão da educação politécnica procurando dimensioná-la, bem como sua importância, nas condições atuais de escolarização da população brasileira.

Palavras-chave educação, trabalho, formação profissional, políticas públicas, cidadania.
Abstract Aiming to maintain a dialogue with the conception of Adriana Geisler, which analyze the meaning of citizenship in Brazil today and propose "identifying to which concept of citizenship the notion of polytechnic is affiliated" the text tries to contribute with the composition of Brazilian social reality structure, showing some reflections as assumed by social rights and the process of governmental policies to establish its totalities in the country. In this sense, the text considers, at first, the meaning of permanent education as a collective social right, and in continuation, since alteration on the nature and performance of the State in the 1990's, it analyzes the changes on the aspects of social rights and public policies of education and work. Finally, it recovers the discussion on polytechnic education trying to measure it, as well as its importance, on current conditions of the education fo Brazilian population.

Key words education, work, professional education, public policies, citizenship 


\section{Introdução}

"Empregamos a pensar alli donde vivimos"

Raymond Willians

Como nos advertem diferentes observadores e estudiosos, a crescente generalização do conceito de 'formação ao longo da vida' remete apenas vagamente ao significado original da matriz da qual procede - o ideal da educação ao longo da vida ou educação permanente, nas expressões inglesa ou francesa. Segundo Licínio Lima (2002 e 2005), a partir do Relatório Faure ("Aprender a ser"), elaborado pela Comissão Internacional para o Desenvolvimento da Educação, da Organização das Nações Unidas para a Educação e a Cultura (Unesco), e publicado há mais de 30 anos, o princípio da educação permanente foi considerado "pedra angular" da "cidade educativa", a "idéia mestra" das políticas educativas futuras. De acordo com esse autor, sua redescoberta, nas últimas décadas, por políticos, economistas e gestores significou uma profunda reconceitualização, que desconhece ou desvaloriza a genealogia do conceito, desvirtuando ou mesmo negando alguns de seus pressupostos políticos mais importantes.

De fato, o conceito de educação ao longo da vida conferia centralidade à educação tanto em termos pedagógicos quanto como objeto de políticas sociais, ou seja, como direito humano básico, responsabilizando o Estado pela garantia das condições de igualdade de oportunidades. O bem comum e a solidariedade assumem o protagonismo nas recomendações da Comissão, que reafirmam concepções historicamente defendidas por educadores democráticos (como, por exemplo, entre nós, Anísio Teixeira e Paschoal Leme), os quais, na vertente do filósofo John Dewey, insistem na circunstância de que 'aprender a ser' significa 'aprender a viver', e de a educação representar a chave de uma democracia participativa.

Nesse sentido, a educação ao longo da vida tornou-se um dos pilares do Estado-previdência, integrada às políticas sociais e redistributivas típicas dos diversos modelos que assumiu em diferentes países após a II Guerra Mundial. O ideal da educação ao longo da vida, conferindo sentido e integrando diversas modalidades e formas de educação/formação, institucionalizadas ou não, era então voltado para a participação e a cidadania democrática, para o desenvolvimento e autonomia dos cidadãos.

Nos anos mais recentes, a reforma liberal do Estado-previdência implicou, entre outros aspectos, em mudanças nas atribuições do Estado em relação à educação, o qual passa a atuar como prestador de serviços educativos/ formativos organizados, tendencialmente, segundo as regras do mercado. Influenciada pelas teorias do capital humano amplamente partilhadas pelos círculos políticos, a noção de formação contínua, continuada ou permanente 
desloca o conceito anterior da educação permanente e atribui ênfase à formação profissional, à sua capacidade de modernização e adaptação funcional à economia e ao mercado. Nesse processo, a responsabilização individual, a racionalidade econômica, o ethos mercantil forçaram não só o deslocamento da educação para a formação, mas também da formação para a aprendizagem. Surge, assim, a 'aprendizagem ao longo da vida' como política educativa do novo Estado neoliberal, orientado para a resolução dos problemas da competitividade econômica e para o reforço das vantagens competitivas de indivíduos, empresas e nações (Lima, 2005). Na perspectiva mais tecnocrática e pragmática, a educação-formação-aprendizagem ao longo da vida transforma-se em panacéia, alavanca de produtividade e solução para os problemas do (des)emprego. E assim fazendo, tal como nos afirma Lima (2002), subordinada à economia, vista como uma variável econômica, a aprendizagem instrumentaliza a vida, amputando-a de suas dimensões não (ou menos) mercantilizáveis, ignorando aspectos substantivos da vida ao longo da aprendizagem.

Estas digressões críticas iniciais têm por objetivo introduzir as concepções de educação e de formação profissional voltadas para o desenvolvimento e consolidação da cidadania, como responsabilidade do Estado e direito do cidadão, ou seja, apontar os pressupostos democráticos que, a nosso ver, devem informar a política pública de organização do sistema nacional de educação.

Tal perspectiva orienta a interlocução que se propõe realizar com as formulações de Adriana Geisler apresentadas no texto "Revisitando o conceito de cidadania: notas para uma educação politécnica". Partindo-se da problematização desenvolvida pela autora acerca do significado da cidadania na sociedade brasileira, e de seu propósito em reconhecer como inscrito no conceito de educação politécnica "um sentido coletivo e emancipatório de cidadania" (distante da visão liberal que orienta o atual projeto conservador de sociedade e de educação escolar no país), são apresentadas algumas reflexões com o objetivo de contribuir para a contextualização do debate. Neste percurso, analisam-se, a partir dos anos 1990, as mudanças ocorridas na atuação do Estado, na configuração dos direitos sociais e das políticas públicas na área social, em especial, as políticas de educação relacionadas às políticas de trabalho, ao mesmo tempo em que se retoma a discussão da politecnia, de modo a situá-la na especificidade da realidade educacional da população brasileira.

\section{A educação permanente como direito social coletivo}

A análise das iniciativas governamentais no campo da educação e de sua relação com o trabalho leva, em primeiro lugar, a se indagar, no que se refere 
às políticas sociais, como elas se conduziram no sentido de firmar a universalidade dos direitos sociais para todos os cidadãos. O que significa percorrer a temática relativa aos modos de compatibilidade entre democracia e capitalismo, discutir a forma da chamada modernidade política, da necessidade de universalização da cidadania e dos direitos e suas instituições reguladoras e mediadoras (Paoli, 1999, p. 11).

Tal como observa Cohn (2004, p. 162), uma primeira questão que importa ressaltar na constituição histórica do modelo de proteção social brasileiro é o fato de as sucessivas formulações e reformulações desse modelo estarem fundadas essencialmente na vinculação dos indivíduos ao mundo do trabalho e, portanto, articuladas ao padrão de reprodução social dado pela sociedade salarial. A partir da legislação previdenciária, trabalhista e sindical instituída no governo Vargas, os direitos sociais vinculam-se à condição dos trabalhadores no mercado formal de trabalho, não sendo, portanto, universais, assim como são contributivos, compulsórios e têm a extensão de sua cobertura para distintas categorias de trabalhadores regulada pelo Estado, configurando-se uma espécie de "cidadania regulada" (Santos, 1979)².

De acordo com a autora citada (Cohn, 1999), o vínculo com a situação formal de trabalho, expresso na articulação da política de Estado de proteção social com o processo de acumulação e desenvolvimento em curso no país até os anos 1980, funda um perfil de atuação do Estado em que cabe a ele cuidar apenas dos segmentos econômicos inscritos nos projetos econômicos, em detrimento das questões sociais. Consolidou-se, assim, um padrão de intervenção pública segundo o qual os investimentos na área social configuravam-se não só como 'gastos', mas como 'gastos residuais', quando se tratava de investimentos em setores como educação e saúde, e, sobretudo, quando se tratava de segmentos sociais não inseridos no mercado de trabalho, apesar de a Constituição de 1988 institucionalizar o conceito de seguridade social e com isso firmar a universalidade dos direitos sociais do cidadão, independentemente de sua situação no mercado.

A lógica deste padrão de intervenção na área social, de proteção social restrita aos inseridos no mercado de trabalho, é "superada com a crise do modelo do estado desenvolvimentista". No entanto, se em relação aos direitos de cidadania a nova Constituição estabeleceu uma regra política democrática e ampliou a proteção social a todos, independente do vínculo formal de trabalho, ao mesmo tempo "assegurou a permanência da velha articulação entre o Estado e o mercado" (Sallum Jr., 2003, p. 39), no momento mesmo em que o processo de transnacionalização e a ideologia neoliberal ganham dimensão mundial.

Há que se destacar, a respeito, que a Constituição de 1988 figura como marco, pela importância que apresenta no sistema jurídico, na medida em que reconheceu a existência de direitos coletivos. De acordo com o jurista 
italiano Mauro Capelletti, citado por Souza Filho (1999, p. 318), a grande diferença entre esses direitos e os direitos individuais, tradicionais, está na relação deles com o Estado. Enquanto os tradicionais devem ser garantidos pelo Estado, os direitos coletivos devem ser promovidos pelo Estado, ou seja, “exigem permanente ação do Estado, com vistas a financiar subsídios, remover barreiras sociais e econômicas, para, enfim, promover a realização dos problemas sociais, fundamentos desses direitos e das expectativas por eles legitimadas". Estes novos direitos têm como principal característica o fato de sua titularidade não ser individualizada; não são fruto de uma relação jurídica precisa, mas apenas de uma garantia genérica a ser cumprida, e que, em seu cumprimento, acaba por condicionar o exercício dos direitos individuais tradicionais. Como nos indica Souza Filho (1999), esta característica os afasta do conceito de direito individual concebido em sua integridade na cultura contratualista do século XIX, porque é um direito sem sujeito, ou melhor, um direito em que todos são sujeitos. Se, de um lado, a partir da Constituição de 1988 passou a ser possível, no sistema jurídico brasileiro, reconhecer como coletivos alguns direitos, ficando essa nova classe de direitos integrada ao ordenamento jurídico, por outro lado, a doutrina e a jurisprudência ainda relutam em tratá-los sob essa denominação e em conferir-lhes efetividade. Apesar das dificuldades de criação e elaboração legislativas, o autor afirma haver inegável avanço na proteção dos direitos coletivos e interesses difusos no que se refere ao consumidor, à proteção do meio ambiente e à defesa do patrimônio cultural, desde que estejam ligados a grupos reunidos em organizações não-governamentais e sindicatos. Estas ações judiciais, como o mandado de segurança coletivo, a ação popular e a ação civil pública, têm limites concretos e razões distintas de existência, mas todas servem à defesa destes direitos. Outros, como os de moradia, acesso à terra, ao trabalho, à saúde, à educação, à assistência social e à segurança, estão criados, mas dependentes de regulamentação concreta para seu exercício. Tal situação gera uma lacuna real no sistema, que, no caso brasileiro, é resolvida ou tem como proposta de solução o mandado de injunção e a ação de inconstitucionalidade por omissão da administração pública, entregando-se ao Judiciário o papel de legislador. Nesse contexto, adverte Souza Filho (1999), a vigência da democracia é um pressuposto ao exercício dos direitos coletivos, à possibilidade de serem exercidos ainda contra a vontade do Estado, no sentido de compeli-lo a agir nas omissões e corrigir ações nefastas. Sem democracia, os direitos coletivos, comunitários, confundem-se com as razões do Estado ou das empresas e perecem ou persistem na forma de simulacro.

Em que pesem os avanços observados no plano legal, o esgotamento do modelo de Estado desenvolvimentista radicaliza a dicotomia econômico versus social na definição das políticas sociais, permanecendo a concepção 
de que gastos na área social são incompatíveis com a estabilidade econômica, o que significa subordinar, mais uma vez, o social ao econômico. Nos anos 1990, a ofensiva neoliberal na sociedade brasileira significou a diminuição do peso do social e do coletivo como parte do sentido político da esfera pública (Paoli, 1999). Sem ser necessário abolir a democracia formal, a estratégia consistiu em instrumentalizá-la para promover o seu ajuste ao movimento do capital, às disposições de um mercado sem limites e sem fronteiras (Souza Santos, 1999). A opacidade da esfera pública está expressa na indefinição de fronteiras entre direitos universais e direitos contributivos e no tratamento dirigido aos setores sociais que estão fora do mercado de trabalho ${ }^{3}$, os quais passam a ser objeto de políticas pontuais, segmentadas, assistencialistas, não regidas pelo paradigma dos direitos sociais ${ }^{4}$.

A nova configuração imposta ao Estado brasileiro, as mudanças de natureza em sua dimensão pública tendem, assim, a transplantar para o seu interior a racionalidade econômica do setor privado, substituindo critérios republicanos de gestão social por critérios privatistas, pautados pela racionalidade do custo/efetividade, que desconhece a dimensão dos direitos sociais (Cohn, 2004). São esses os parâmetros que orientariam o debate 'social' e a ação pública sobre a questão da universalização versus focalização e da centralização versus descentralização das políticas e dos programas sociais.

Estas dicotomias e outras dissonâncias que têm marcado as políticas sociais em nosso país não são procedentes, uma vez que qualquer projeto setorial implica ações centralizadas e ações descentralizadas, assim como se fazem necessárias políticas universais e focalizadas articuladas entre si e pautadas pelas premissas dos direitos sociais, dada a heterogeneidade do país, as desigualdades nele presentes. Se, na (re)definição das estratégias de implementação de políticas públicas, princípios éticos impõem as prioridades imediatas aos mais pobres, estas políticas não podem perder de vista a matriz da perspectiva dos direitos universais. Nessa direção, como bem assinala Cohn (2004), entende-se ser o Estado a única instituição social que possui instrumentos efetivos de redistribuição de riquezas em nossa sociedade, capaz, portanto, de formular e implementar políticas de caráter estruturante, e não somente políticas emergenciais e conjunturais. Tal posição implica em redirecionar o tema

“(...) para um outro patamar de reflexão que não se limite à racionalização gerencial das políticas sociais, buscando-se adequar as políticas compensatórias, que se restringem ao universo da naturalização da pobreza enquanto fenômeno social, a politicas emancipatórias, que visem à inserção social dos segmentos socialmente excluídos da sociedade por insuficiência de recursos sociais. O que está em jogo atualmente é exatamente buscar uma relação virtuosa entre as dimensões econô- 
micas e sociais das políticas, resgatando as políticas sociais, elas também como políticas essencialmente econômicas, mas que como tal devam ser regidas não pela lógica do crescimento do setor produtivo da economia, mas pelas políticas de inserção ditadas pelos parâmetros dos direitos universais" (Cohn, 2004, p. 173, grifo nosso).

Mas isso ainda não é suficiente. Faz-se necessário, como enfatizam a mesma autora, Castel (1998) e Souza Santos (1999), enfrentar a questão social no país, pautada pela desigualdade social, não pelos seus efeitos, pelas conseqüências inerentes ao próprio mercado (desigualdades de renda e condições de vida por gênero, etnia e geracionais, por exemplo), mas agindo sobre as contradições sociais que estão na origem dessas desigualdades. Trata-se, então, de articular os sistemas de proteção social entre si (os de caráter diretamente contributivo, vinculados ao mercado de trabalho ou ao acesso à renda, e os de caráter não contributivo, relativos aos benefícios sociais assistenciais, financiados com recursos orçamentários) e com as políticas econômicas de caráter estrutural que visem promover a autonomia dos indivíduos em relação ao acesso à garantia de renda. Trata-se, enfim, de redefinir a qualidade da relação Estado-sociedade, tornando essas políticas promotoras de uma nova relação que fortaleça a esfera pública, democratize o Estado e permita o exercício autônomo da cidadania.

Dessa maneira, assume especial importância a dimensão propriamente pública das políticas públicas, quaisquer que sejam elas e, em particular, as políticas de educação e formação profissional voltadas aos jovens e adultos trabalhadores, na ampla acepção de educação permanente como direito universal de cidadania. Isto nos leva à necessidade de detectar e implementar mecanismos criativos de controle público, de forma a viabilizar a participação dos coletivos sociais na definição das políticas públicas, promovendo a publicização do Estado e fazendo com que as políticas se transformem em instrumento valioso de emancipação dos indivíduos em relação ao Estado.

\section{Educação, trabalho e políticas públicas}

Do ponto de vista da educação, como indicam Frigotto e Ciavatta (2003, p. 97), ocorreu, nos anos 1990, uma disputa entre o ajuste dos sistemas educacionais às demandas da nova ordem econômica e as demandas por uma efetiva democratização do acesso ao conhecimento em todos os níveis. Antes do governo Fernando Henrique Cardoso, o Brasil vivenciou uma década de intensos debates na transição do governo civil-militar para a redemocratização. O centro desse debate foi canalizado para o processo Constituinte e, em seguida, para a elaboração da nova Constituição (1988). Pode-se supor, conforme os autores, que o capítulo da ordem econômico-social incorporou 
teses do projeto de desenvolvimento 'nacional popular' e alcançou ganhos significativos na afirmação dos direitos econômicos, sociais e subjetivos. Nesse contexto, os educadores, através de suas entidades científicas, culturais e sindicais, que resistiram ao período ditatorial, protagonizaram inúmeras experiências em prefeituras e em alguns estados, como nos mostra Cunha (1991), e iniciaram a construção do projeto de nossa segunda LDB e do Plano Nacional da Educação.

Mas como observamos, a travessia para a democracia ficou inconclusa. Os ajustes da economia brasileira ao novo contexto econômico foram acompanhados da presença de organismos internacionais que passaram a orientar as reformas na educação em termos organizacionais e pedagógicos. As demandas da sociedade organizada foram, então, substituídas por medidas produzidas por especialistas e tecnocratas, geralmente assessores destes organismos multilaterais. Um dos problemas que se pode apontar no conjunto do projeto educacional desenvolvido nos anos 1990 consistiu no centralismo das decisões na formulação e na gestão da política educacional, ao mesmo tempo em que se observa, no plano federal, uma tendência à diminuição da presença do poder público nas tarefas de manutenção e desenvolvimento do ensino, através de mecanismos de envolvimento de pais, organizações não-governamentais, empresas.

No entanto, num movimento contrário, tal como apontam estudos a respeito do desenvolvimento da educação no país, a sociedade brasileira tem reivindicado historicamente o fortalecimento da escola pública estatal e a democratização da gestão educacional como eixos do esforço de universalização do ensino básico e, progressivamente, do ensino superior. Na prática, isto significaria passar de um investimento de $4 \%$ do PIB em educação, para $10 \%$ ao final de dez anos do Plano Nacional de Educação (Frigotto e Ciavatta, 2003, p. 113), atribuindo-se, assim, centralidade ao caráter público da educação.

Ainda no campo dos problemas apresentados pela educação brasileira, se houve efetiva melhora nos indicadores básicos da escola fundamental neste início de século XXI, os desafios localizam-se nas condições de ensino e de trabalho dos professores. De acordo com dados fornecidos pelo Instituto Brasileiro de Geografia e Estatística (IBGE) e o Departamento Intersindical de Estatística e Estudos Sócio-Econômicos (Dieese), a taxa de analfabetismo da população com 15 anos ou mais de escolaridade atinge, em 2004, $11,6 \%$. Na região Sudeste, onde se situa o Estado de São Paulo, o índice de analfabetos é menor, $6,8 \%$. Neste grupo, no entanto, não estão incluídos os 'analfabetos funcionais', que só têm até três anos de escolaridade e apresentam sérias dificuldades de leitura e escrita.

Embora a taxa de analfabetismo tenha diminuído, o nível de instrução média da população continua baixo. Segundo o IBGE, em 2003, a popula- 
ção de 25 anos ou mais, masculina e feminina, apresentou, em média, seis anos de estudos, ou seja, não chegou a completar os sete anos do ensino fundamental. As disparidades regionais também persistem. Na região Nordeste, o nível de instrução da população com dez anos ou mais atingiu o patamar mais baixo: cinco anos de estudo, em média. A região Sudeste, por sua vez, manteve-se na liderança: sua população com sete anos de estudo, em média.

Atualmente, o Brasil, segundo informações do Censo Escolar promovido pelo Instituto Nacional de Estudos e Pesquisas Anísio Teixeira (Inep), em 2004, tem cerca de 55 milhões de estudantes nos diferentes níveis e modalidades da educação básica. Desse total, $88 \%$ estão em escolas públicas. O ensino fundamental concentra 34 milhões de matrículas e o ensino médio regular, 9,2 milhões. Observa-se, portanto, a persistência do afunilamento das matrículas, indicativo do caráter seletivo da educação brasileira. Quanto ao ensino superior, apenas 3,9 milhões de alunos matricularam-se em cursos de graduação.

Os estudos do Inep mostram também que $41 \%$ dos estudantes não terminam o ensino fundamental, e os que concluem levam, aproximadamente, dez anos para completar as oito séries. Nesse nível de ensino, 39\% têm idade superior à adequada para a série que cursam; no ensino médio, esse índice é de $53 \%$.

Os dados indicam a discriminação dos afrodescendentes, cuja participação diminui fortemente à medida que aumenta o nível de escolarização. No ensino fundamental, os pretos e pardos representam 53,2\% do total e alunos, e os brancos são 46, 4\%. No ensino médio, a proporção de negros e pardos é de 43,9\%, e na educação superior, 23,1\%. Já na pós-graduação, o índice de participação dos afrodescendentes é de 17,6\%, enquanto os brancos somam 81,5\% do total, segundo indicadores do IBGE de 2002, tabulados pelo Inep. Em relação ao número de anos de estudo no país, a população branca tem, em média, sete anos e a população negra ou parda, cinco.

Além disso, as avaliações nacionais, promovidas a partir dos anos 1990 pelas diferentes esferas governamentais, e também pelas internacionais, têm indicado a ineficiência do sistema escolar em oferecer ensino de qualidade. O baixo desempenho dos alunos em escrita, cálculo, localização geográfica e histórica deram o tom da crise da educação brasileira no final do século XX (Bomeny, 2001). Tais resultados levam empresários e governos a afirmar o despreparo da população para a vida em uma sociedade urbana industrializada, a 'sociedade da informação' ou a 'sociedade do conhecimento'. Enfatiza-se, então, a inoperância da escola básica no preparo dos indivíduos para o mercado de trabalho.

A concepção econômica da educação, hegemônica no discurso dominante, subordina a escola aos imperativos do mercado e também associa 
escolaridade com conquista de emprego ou de melhores chances de trabalho. Como bem observa Bomeny (2001, p. 67), a 'empregabilidade' passa a ser indicador de discriminação, ou seja, discrimina-se, com objetivos de avaliação e mensuração, os que têm instrumentos para competir no mercado e os que sequer tiveram acesso às informações exigidas para a competição. Em pouco mais de um século, migramos da sociedade escravocrata que associava trabalho a condenação, para outra, que associa falta de trabalho a incompetência.

Visando superar deficiências e adequar o ensino às novas demandas econômicas, o governo anterior, seguindo os parâmetros dos organismos multilaterais, em especial o Banco Mundial (BIRD), realizou reformas na educação média. Com o decreto $\mathrm{n}^{\circ} 2.208$, de 1997, que reformulou o ensino técnico e criou o Sistema de Educação Profissional, retrocedeu-se ao dualismo estrutural entre ensino acadêmico e ensino técnico.

$\mathrm{O}$ atual governo emitiu um novo decreto ( $\left.\mathrm{n}^{\circ} 5.154 / 04\right)$, que substitui a medida anterior e reintegra a educação profissional técnica ao ensino médio, e desde então o Ministério da Educação (MEC) vem tomando medidas no sentido de propiciar o amadurecimento de orientações para a implementação do ensino médio integrado, para a superação organizacional e pedagógica da separação entre formação geral e técnica, entre ciência, técnica e tecnologia. A superação da dualidade no ensino, no entanto, só se efetivará a partir da formulação de políticas públicas que levem em conta a situação dos trabalhadores jovens e adultos que apresentam baixos índices de escolaridade formal e desempenho escolar. Temos, no Brasil, aproximadamente 70 milhões de pessoas, com mais de 18 anos, sem escolaridade média concluída. Dos brasileiros na faixa etária de 25 a 34 anos, classificados como população adulta jovem, $24 \%$ concluíram o ensino médio e $6 \%$ terminaram o ensino superior. Outros $70 \%$ têm, no máximo, o ensino fundamental, sendo que 5,5\% não possuem qualquer grau de instrução (MEC/Inep, 2003-4).

Associando-se a este quadro a situação de trabalho, verifica-se que, entre os ocupados (68.040.206 trabalhadores de 87.787.660, da população economicamente ativa), a maioria, ou seja, 42,8\% começaram a trabalhar entre 10 e 14 anos, isto é, antes da idade legal $(46,2 \%$ homens e 38\% mulheres). Em 2003, das 16.286.941 crianças nessa faixa etária, há 1.872.745 $(11,5 \%)$ trabalhando no campo e nas cidades. Ao acrescentarmos aquelas que trabalham e tem entre cinco e nove anos, teremos mais 208.931 crianças ampliando os índices do trabalho infantil, que atinge 1.897 .602 crianças. Por outro lado, são altas as taxas de desemprego dos jovens e adultos entre 15 e 39 anos, que variaram, em 2004, nas regiões metropolitanas, da maior para a menor, respectivamente: entre 15 e 17 anos, de 45,6\% (Recife) a 63,9\% (Distrito Federal); entre 18 e 24 anos, de 30\% (São Paulo) a 41,8\% (Salvador); e entre 25 e 39 anos, de 14,6\% (Porto Alegre) a 24,8\% (Salvador). Embora 
o desemprego nos mercados de trabalho metropolitanos seja elevado para o conjunto dos jovens, a população feminina está mais vulnerável à situação de desemprego, particularmente na faixa entre 16 e 24 anos, sendo que os maiores índices registrados estão em Recife $(48,2 \%)$ e Salvador $(47,6 \%)$ e o menor em Belo Horizonte (33, 9\%). Por fim, observando-se a distribuição dos jovens de 16 a 24 anos, segundo a situação de trabalho e estudo, vemos que o número dos que só trabalham ou procuram trabalho nas diferentes capitais do país superam e muito os que trabalham e estudam ou só estudam, variando de 50,5\% (São Paulo) a 36, 6\% (Salvador e Recife) 5 .

Tais circunstâncias impõem, como discutimos ao longo do texto, políticas públicas democráticas que enfrentem as necessidades conjunturais, emergenciais, atendam a particularidade e a diversidade das demandas sociais - jovens e adultos, homens e mulheres de diferentes etnias, empregados e desempregados - e, ao mesmo tempo, políticas que realizem mudanças ou reformas estruturais e promovam a superação da atual estrutura social geradora da desigualdade. Uma política pública redistributiva e emancipatória seria aquela capaz de retirar do mercado de trabalho, formal e informal, todas as crianças e jovens até a idade legal de conclusão do ensino médio6, o que pressupõe o desenvolvimento de iniciativas que combinem medidas na área da educação e da formação profissional e o acesso a programas de transferência de renda aos jovens em situação de vulnerabilidade e risco social, conforme reivindicação de movimentos sociais e insistente recomendação de especialistas, com ensaios bem ou mal sucedidos do governo atual. Sabe-se que, por sua vez, o êxito dessas políticas exige a extensão, nos próximos anos, da obrigatoriedade do ensino médio para todos os jovens que completarem o ensino fundamental até a idade de 16 anos. Por outro lado, o acesso dos trabalhadores jovens e adultos à educação básica e à formação profissional depende da imediata regulamentação legal da jornada de trabalho, de maneira a definir o número de horas destinadas à realização dos estudos e de atividades culturais. Por fim, e sobretudo, o direito ao trabalho só pode ser assegurado por uma trajetória de crescimento econômico sustentado que possibilite equacionar o problema do desemprego e propiciar a geração de empregos qualificados, trabalho e renda.

Nessa perspectiva, as medidas desenvolvidas pelo atual governo expressam clara disputa entre propostas que se orientam na direção da continuidade das políticas neoliberais herdadas, de flexibilização e mercantilização dos direitos sociais, e aquelas que propõem a implementação de um projeto voltado para a construção de um modelo alternativo de desenvolvimento econômico e social democrático. O embate é perceptível nas dificuldades de implementação de políticas universais, permanentes, substituídas por uma multiplicidade de políticas públicas de caráter provisório e assistencialista, fragmentadas em vários ministérios no nível central do governo. 
É importante ressaltar, a esse respeito, algumas iniciativas que mostram o intento do MEC e do Ministério do Trabalho e Emprego (MTE) em superar estes problemas por meio do desenvolvimento de políticas integradas de educação e trabalho voltadas para a inclusão social e o resgate da cidadania, as quais apresentam uma convergência com reivindicações apresentadas por entidades representativas dos educadores e do movimento popular ao governo Lula, e discutidas, no início da gestão, em seminários organizados pelos ministérios citados?

No que se refere ao MEC, trata-se do Programa de Integração da Educação Profissional ao Ensino Médio na Modalidade de Educação de Jovens e Adultos - Proeja (decreto $\mathrm{n}^{\circ} 5.478$, de 24 de junho de 2005, e decreto $\mathrm{n}^{\circ}$ 5.840, de 2006), destinado ao atendimento daqueles (milhões) de trabalhadores que não concluíram a educação básica na idade própria, apresentam defasagem idade/escolaridade e por causa disso têm dificuldades de acesso a cursos técnicos de qualidade que lhes propiciariam melhorar suas condições de exercício profissional.

É preciso demarcar o avanço considerável realizado pelo programa ao propor a integração da formação profissional inicial à educação básica na modalidade educação de jovens e adultos (EJA), criando canais de comunicação e viabilizando sua continuidade na educação profissional técnica de nível médio. Buscando valorizar a especificidade e a qualidade do ensino de adultos, a medida determina a construção prévia de um projeto pedagógico integrado único, além de prever o reconhecimento, pelas instituições ofertantes, de conhecimentos e habilidades obtidos pelos alunos em processos formativos extracurriculares mediante avaliação individual. Está prevista, também, a possibilidade de o aluno que demonstrar, a qualquer tempo, aproveitamento no curso vir a obter o diploma, com validade nacional, tanto para fins de habilitação técnica como de conclusão do ensino médio, possibilitando-lhe o prosseguimento dos estudos no nível superior. Outro aspecto relevante é o fato de se prever que a implantação do programa de ensino viesse a ocorrer em instituições federais, preparadas e equipadas para realizar um ensino de qualidade.

Acrescente-se a isso a determinação da construção de itinerários formativos para os cursos de formação profissional inicial e continuada, na área profissional escolhida (em sintonia com as demandas de nível local e regional), providência que pretende intervir na regulamentação desse tipo de formação, a qual permanece, até hoje, na forma de cursos livres, não sujeitos à regulamentação do $\mathrm{MEC}$, sem qualquer tipo de orientação normativa que permita a validação dos conhecimentos, seja para a classificação funcional da ocupação, seja para posterior aproveitamento dos estudos.

A designação "formação profissional inicial e continuada", introduzida pelo decreto $\mathrm{n}^{\circ}$ 5.154, de 2004, vem substituir a de "educação profissional 
básica" (decreto n 2.208, de 1997), que se configurava como nível do Sistema de Educação Profissional, estrutura paralela à organização da educação básica e superior. Objeto de oferta pública e privada, por entidades empresariais, empresas, sindicatos e organizações não-governamentais, estes cursos, em geral, caracterizaram-se por serem de curta duração, descontínuos e de baixa qualidade.

O decreto atual não define formação profissional inicial e continuada, mas propõe sua integração à educação básica na modalidade de EJA, entendendo que a educação escolar constitui a base da formação profissional inicial e continuada, sendo esta um complemento daquela. Dessa maneira, o direito à formação profissional integra o direito à educação (permanente). Esta concepção de formação profissional rompe com o significado atribuído, no governo Fernando Henrique Cardoso, à formação, anunciada em termos de competência, de ações de reciclagem, de adaptação às atividades do mercado.

A formação vinculada à noção de competência, que, por sua vez, é construída sob “o registro do cognitivo, da ação e dos comportamentos (saber, saber fazer e saber ser)" (Tanguy, 2003), é vista como um conjunto de meios a serviço de certas finalidades, isto é, de ajuste às demandas imediatas e pontuais das empresas. Estes objetivos, traduzidos na legislação educacional herdada do governo passado ${ }^{8}$, e ainda atuais no discurso dominante, informam a organização da maioria da imensa quantidade de cursos e programas de formação ou qualificação profissional, os quais, apesar das iniciativas do MTE, continuam a ser um "sistema regulado pelo mercado" (IPEA, 2006), com conseqüências previsíveis: a ampliação da hierarquização da força de trabalho, o aprofundamento da distância entre os trabalhadores qualificados e os não qualificados, em resumo, a ampliação e o aprofundamento da desigualdade social.

Com o objetivo de intervir nessa situação e regulamentar a oferta de formação, o governo tomou algumas iniciativas, ainda que tímidas, para a formulação de políticas públicas que visem à regulamentação e ao desenvolvimento da formação profissional no país. Nessa direção, o Plano Nacional de Qualificação (PNQ) - que substituiu o Plano Nacional de Formação (Planfor) -, além de moralizar o uso dos recursos públicos, introduziu modificações na condução da política de qualificação profissional, promovendo a resignificação de suas noções ordenadoras. Entre elas, há de se considerar a substituição da noção de competências pela noção de 'qualificação social e profissional', o que expressa mudanças significativas na concepção de trabalho, educação, formação profissional e da relação entre elas, e, em decorrência, nos processos de formação e certificação.

No entanto, ainda há muito por realizar, isto é, faz-se necessário implementar critérios e procedimentos que possibilitem transformar as novas 
orientações em medidas concretas. É preciso, entre outras providências, acelerar aquelas que tornem possível integrar a formação profissional inicial à educação básica ( $80 \%$ dos cursos não exigem escolaridade mínima), e que viabilizem a construção de itinerários formativos como eixo da normatização e da organização dos cursos. A identificação de possíveis trajetórias ocupacionais que referenciem a construção dos percursos de formação diferenciados e dos diferentes perfis de qualificação, isto é, o planejamento da formação, exige que se conheça o mercado de trabalho - formal e informal - de maneira antecipada. É preciso conhecer o movimento do emprego/desemprego, as mudanças nas profissões, no conteúdo das ocupações, e a oferta da formação na perspectiva dos diferentes setores econômicos (novas tecnologias, inversões, mercados, etc.) e do desenvolvimento territorial - nacional, regional, local (cadeias produtivas, empresas, acordos e planos de geração de emprego, trabalho e renda) (Moraes e Lopes Neto, 2005). Não dispomos, ainda, de estudos sistemáticos, que somente um observatório nacional permanente das situações de trabalho e formação poderia produzir, e sem esses estudos e pesquisas não se pode identificar e distinguir as desigualdades presentes no mercado de trabalho, que tendem a se reproduzir na oferta da formação profissional, não se pode planejar e implementar uma política pública de formação profissional, não se pode formular políticas de caráter emancipatório.

Na direção dessas preocupações, o MTE (Secretaria de Políticas Públicas de Emprego, Departamento de Qualificação - DEQ) e o MEC (Secretaria de Educação Profissional e Tecnológico - SETEC) estão desenvolvendo, desde 2003, um projeto de política pública que tem como objetivo principal a construção negociada de um Sistema Público Nacional de Certificação Profissional (SNCP). A proposta está sendo desenvolvida na contracorrente de iniciativas de 'certificação profissional baseada em competências' promovidas pelo mercado. É possível notar que, na última década, houve uma ofensiva do empresariado no sentido de criar um sistema que transferisse a responsabilidade do Estado para o setor privado e excluísse a participação negociada com a representação dos trabalhadores. Como resultado, tais políticas realizam-se hoje de forma isolada, desvinculada das políticas de educação/ formação profissional e certificação de escolaridade. Os movimentos de certificação da ISO 9.000 e 14.000, que incluem programas de qualidade, impulsionaram processos de certificação no país. Segundo os dados do Comitê Brasileiro de Qualidade (CB-25), da Associação Brasileira de Normas Técnicas (ABNT), em 2004, havia o registro oficial de 3.500 certificados, número quatro vezes maior que o de 1995. De acordo com pesquisa desenvolvida pela revista Exame (2005, p. 14-17) em 222 empresas, cerca de $84 \%$ delas estão envolvidas com a ISO 9.000 e quase todas exigem que seus fornecedores, distribuidores e/ou clientes apliquem os novos métodos. Tais 
informações levaram uma análise do IPEA (2006, p. 216) a prever a rápida propagação dos efeitos desta prática pelas cadeias produtivas, “atingindo a maioria da força de trabalho do mercado formal e até mesmo do informal (extrativistas, produtores domésticos, cooperados etc.)".

Tanto no plano nacional como no internacional, a lógica da competência configura-se "como um dos elementos centrais e articuladores da livre concorrência dos trabalhadores nos processos produtivos" (Fidalgo, 1999). Na maioria desses modelos de certificação de competências, o processo de aprendizagem não é considerado central, seu conteúdo não é precisado (leva-se em conta a capacidade de realizar uma tarefa conforme a norma) e a competência pode ser avaliada na ausência de toda a ação formativa ou de escolaridade. Nestas circunstâncias, não é difícil imaginar a relevância da intervenção da política pública na regulação deste mercado de certificação, indutor e reprodutor de desigualdades sociais.

Esta concepção 'renovada' de formação continuada, que se caracteriza basicamente pelo seu caráter mercantil e pela desigualdade de acesso dos trabalhadores à educação escolar e à formação profissional continuada, como mostra Beynon (1999), é parte do projeto neoliberal de abandono dos benefícios sociais como direitos, da destruição das bases de negociação coletiva e da mediação sindical, da desconstituição da representação organizada nas fábricas, da superação da greve como forma de protesto em defesa dos direitos e garantias sociais. Citando o exemplo da Grã-Bretanha, assinala mudanças operadas não só na legislação sobre direitos, como também a transformação do significado da expressão 'direitos coletivos' em 'responsabilidades individuais', de modo que não há mais direito ao trabalho, mas sim a tarefa individual de se educar para conseguir um lugar no mercado de trabalho ('treinar para trabalhar'), e isto passa a ser entendido como 'direitos individuais', e o que o indivíduo consegue não pode ser estendido à sociedade como direito de todos.

Na mesma direção, Neyrat e Pélage (2005, p. 143-144) observam, no caso da França, a curiosa lógica presente nesta concepção de que é preciso partir do indivíduo para construir direitos, e no caso, o direito à formação continuada: enquanto as desigualdades de formação inscrevem-se e encontram sua origem nas relações sociais, notadamente nas relações de classe, de gênero, na concorrência entre grandes e pequenas empresas, entre setores de atividades, pretende-se poder 'corrigir' estas desigualdades do ponto de vista individual. Ou seja, centrada no indivíduo, a questão principal não é mais a da desigualdade entre indivíduos, "mas aquela do 'reconhecimento' do indivíduo, um reconhecimento largamente simbólico, e o direito novo participa aqui afirmando... o caráter individual do direito à formação". Retomando Norbert Elias, os autores argumentam que, enquanto as interdependências sociais são cada vez mais fortes entre os indivíduos, a pessoa 
é cada vez mais levada a se pensar fora do grupo, a se definir como um "eu sem nós", E esta forma de "cegueira sobre articulação da identidade do nós e da identidade do eu não ocorre sem conseqüências". Segundo eles, a validação das aquisições da experiência (VAE), uma das formas mais recentes de formação continuada, instituída na França pela chamada 'lei da modernização social', de 2002, de acordo com recomendações da Comunidade Européia e da Organização para a Cooperação Econômica e o Desenvolvimento (OCDE), representa uma regressão, uma "involução do coletivo ao individual", na medida em que dissocia a certificação da formação, colocando em risco o direito dos trabalhadores não só à formação profissional, mas também à educação escolar. Em síntese, consiste em mais um instrumento de 'desregulação', porque ameaça direitos coletivos.

As preocupações esboçadas por estes autores de países centrais do capitalismo sobre a situação de regressão social, de perda dos direitos sociais, de desmonte dos direitos coletivos, leva a pensar na nossa especificidade como país que não teve a possibilidade histórica de afirmação e consolidação de muitos dos direitos garantidos nas diversas versões do Estado de bem-estar. Isto de certa maneira também orienta a disputa política pela defesa, entre nós, desses mesmos direitos. Nessa direção, cumpre destacar a relevância de iniciativas conjuntas entre o MTE, o MEC e outros ministérios na construção do SNCP, o qual tem por meta a luta pela inclusão, a inversão da tendência de aumento das desigualdades, permitindo aos menos formados e aos menos qualificados o acesso à escolaridade e às qualificações superiores. Em outras palavras, o SNCP deve valorizar as iniciativas individuais, conservando a arquitetura do direito coletivo (Dubar, 2004).

Em termos organizacionais, isso significa, em primeiro lugar, integrar os 'sistemas' de educação e formação existentes no país e avaliar e certificar os conhecimentos do indivíduo, independentemente das vias que seguiu para obtê-los. Em segundo lugar, somente o diálogo e a participação sociais, a integração dos atores sociais - escolares, econômicos e políticos - nos planos locais e nacional, podem assegurar legitimidade e eficácia sociais à política pública de formação e certificação profissional, de forma que ela, por sua vez, possa propiciar a inserção dos trabalhadores em empregos qualificantes e o desenvolvimento de formações inovadoras ligadas a esses empregos. Nessa direção, tanto a integração das políticas de formação e certificação às políticas de desenvolvimento (locais, regionais e nacional) e ao sistema público de emprego, como a vigência de relações democráticas de trabalho (comissão de trabalhadores nas empresas, representação setorial e negociação coletiva) consistem em seus pressupostos fundamentais.

É preciso diferenciar programas como o Proeja, propor o seu aperfeiçoamento e ampliação, de maneira que venha a constituir-se em política pública permanente, que substitua programas polêmicos como o Escola de Fábrica e 
o ProJovem, por exemplo, concentrando esforços e recursos, redirecionando o uso dos recursos públicos para a escola pública, visando a expansão do atendimento a públicos cada vez mais amplos e a melhoria da qualidade do ensino. Nessa mesma perspectiva, seria desejável o diálogo dessa política com o Plano Nacional de Qualificação e de ambos com as ações do SNCP.

Como exigência para a efetiva democratização da oferta de formação, faz-se necessário que todos os recursos públicos destinados à educação/formação profissional tenham gestão pública. No caso do Sistema $S$, de financiamento público e gestão privada, deve ser providenciada a sua gestão pública. Nessa estrutura, além dos recursos públicos, as empresas devem estar obrigadas a contribuir com o financiamento da formação continuada/ aprendizagem.

O conjunto dessas medidas caminha no sentido do resgate e da revitalização da educação de jovens e adultos, de modo a superar o viés assistencialista e compensatório, promovendo a inclusão social. É importante sublinhar a estreita relação entre a ação pública em matéria de educação de adultos e as mudanças sociais, econômicas e políticas, mais visíveis neste domínio do que em outros do sistema escolar (Rubenson, 2001). A esse respeito, basta recordar o abandono da EJA no governo Fernando Henrique Cardoso, quando foi colocada em segundo plano na reforma de 1990 (orientada para a focalização dos recursos públicos no ensino fundamental de crianças e adolescentes) e as matrículas de jovens e adultos foram expurgadas do Fundo de Manutenção e Desenvolvimento do Ensino e Valorização do Magistério (Fundef) por veto do então presidente ${ }^{9}$. Espera-se, a esse respeito, que o projeto de constituição do Fundo de Manutenção e Desenvolvimento da Educação Básica (Fundeb), que propõe englobar todos os recursos vinculados ao conjunto da educação básica (educação infantil, fundamental e média), incluindo a EJA, venha, uma vez aprovado, a contemplá-la com os indicadores pertinentes às suas necessidades ${ }^{10}$. Ao mesmo tempo, torna-se imprescindível fomentar um amplo debate sobre o Sistema S, as escolas técnicas federais e estaduais, e suas atribuições nas políticas de educação de jovens e adultos.

Nesse momento em que a formação torna-se, como vimos, uma espécie de 'braço longo da empresa', trata-se, mais do que nunca, de revitalizar, fortalecer e ampliar a EJA, organizá-la "como meio de luta contra a hegemonia das forças do mercado" (Rubenson, 2001, p. 228). Para isso, a proposta de organização pedagógica do ensino integrado é um pressuposto, tanto no ensino de adultos quanto na escola média dirigida aos jovens na idade própria. Segundo Gramsci (1972), a conquista da hegemonia, a luta pela liderança moral, política e intelectual na vida social, isto é, a construção de uma "unidade cultural", pelos trabalhadores, por meio da difusão de sua própria "visão do mundo" no tecido social como um todo, atribui importância estratégica à instituição escolar. Sua concepção de escola única, 
politécnica, que tem o trabalho humano como 'princípio educativo', será a principal referência teórica contra a visão economicista da educação e seu contraponto organizacional, a escola dual.

Para romper a trama da "escola tradicional", pondera Gramsci (1972, p. 127), "não se deve multiplicar e graduar os tipos de escola profissional, senão criar um tipo único de escola preparatória (elementar-média) que leve o jovem até o umbral da eleição profissional, formando ao mesmo tempo uma pessoa capaz de pensar, de estudar, de dirigir ou de controlar o que dirige"11. Propõe que a última etapa da escola unitária seja

“(...) concebida e organizada como etapa decisiva capaz de criar os valores fundamentais do 'humanismo', e a autodisciplina intelectual e a autonomia moral necessárias à posterior especialização, seja de caráter científico (estudos universitários), seja de caráter imediatamente prático-produtivo (indústria, burocracia, etc.). $\mathrm{O}$ estudo e a aprendizagem dos métodos criativos na ciência e na vida deve começar nesta última etapa da escola e não ser mais um monopólio da universidade, ou deixado ao acaso da vida prática; esta etapa escolar deve contribuir para desenvolver o elemento da responsabilidade autônoma nos indivíduos, deve ser uma escola criativa" (Gramsci, 1972, p. 117).

Essas recomendações contribuem para a reflexão e o amadurecimento da proposta de ensino médio integrado, se necessariamente deve ter como fundamento a profissionalização ou se deve viabilizar a apropriação dos princípios científicos, dos conhecimentos teóricos e práticos necessários, sobre os quais se funda a organização do trabalho moderno e o conjunto da vida social. Nesta acepção, “a profissionalização viria após uma sólida formação geral" (Werlang, 2006), o que significa, de certa maneira, retomar o fio do debate realizado pelo Fórum Nacional em Defesa da Escola Pública no decorrer das diferentes etapas de elaboração da última LDB.

De qualquer forma, o que importa ressaltar aqui é a importância do 'trabalho' como noção ordenadora da proposta pedagógica de ensino integrado, ou escola unitária, para a educação básica de nível médio, incluindo a modalidade EJA, que deve ter "como eixo central a articulação entre ciência/conhecimento, cultura e trabalho" (Frigotto, 2004b). Parece desnecessário dizer que não estamos nos referindo ao trabalho assalariado, coisificado, estranhado, produtor de valores de troca, mas ao trabalho como criador de valores de uso, em sua dimensão concreta, enquanto atividade vital; ao trabalho como responsável pela relação do homem com a natureza e com o outro homem, fonte originária, primária da realização do ser social, da construção da humanidade do homem, tal como mostra Marx em seus Manuscritos econômicos e filosóficos de 1844. Nesse sentido central e emancipador, a noção de trabalho constitui-se como mediadora na integração dos 
diferentes saberes e áreas de conhecimento necessárias à compreensão dos diversos âmbitos da vida social, individual e coletiva. No ensino de adultos, a percepção crítica do trabalho humano leva à apreensão de novas dimensões no saber e no cotidiano do trabalhador, ao resgate de suas experiências, ao seu reconhecimento como sujeito dos processos de ensino, convertendo a educação "em guia do descobrimento coletivo", "em uma "comunidade da experiência' e da igualdade humana e intelectual" (Willians, 1981).

\section{Notas}

${ }^{1}$ Professora associada da Faculdade de Educação da USP e membro do Conselho Científico Intercâmbio, Informação, Estudos e Pesquisas (IIEP). <moraescs@usp.br>

2 Sobre a história do sistema de proteção social brasileiro, consultar, além deste, Amélia Cohn (1980) e Ignácio Delgado (2001), entre outros.

3 Em 2003, dos 79.250.627 trabalhadores ocupados no país, apenas 36.739.070 eram contribuintes da previdência social, segundo dados da PNAD/IBGE (Dieese, 2005).

${ }^{4}$ De acordo com Amélia Cohn (2004), o segmento previdenciário, contributivo, também passa a ser interpretado como gasto, uma vez que conta, para parte de seu financiamento, com recursos orçamentários. Em conseqüência, a 'flexibilização' dos direitos sociais securitários historicamente conquistados, desvinculando-os da situação dos indivíduos do mercado de trabalho. A desvinculação da base contributiva da previdência social, realizada no segundo mandato de Fernando Henrique Cardoso, a substituição do tempo de trabalho pelo tempo de contribuição como critério de aposentadoria significa, para a autora, a radicalização do império da racionalidade contábil da saúde financeira/orçamentária da previdência social sobre a racionalidade da proteção social em relação aos trabalhadores portadores do vínculo formal de trabalho.

${ }^{5}$ Fonte: Departamento Intersindical de Estatística e Estudos Sócio-Econômicos (Dieese)/ Fundação SEADE/MTE/PED - Pesquisa Emprego e Desemprego. Elaboração: DIEESE, 2005.

6 Para uma análise detalhada da situação de trabalho e educação da juventude brasileira, e dos desafios a serem superados por políticas públicas na área, consultar Frigotto (2004a) e Branco (2005).

7 Seminário Nacional Educação Profissional, Concepções, Experiências, Problemas e Propostas (MEC, 16 a 18 de junho de 2003); Seminário Nacional de Certificação Profissional do Segmento Governamental (MTE, 09 e 10 de setembro de 2003), ambos realizados em Brasília.

8 É imprescindível que os parâmetros e diretrizes curriculares nacionais do ensino médio e do ensino técnico (pareceres Conselho Nacional de Educação/CNE - Câmara de Educação Básica/CEB, nº 15/98 e n 16/99), responsáveis pela introdução da noção de competência como referencial na organização curricular e de itinerários formativos no ensino 
técnico, sejam urgentemente revistos, substituídos por novas orientações curriculares. Da mesma maneira, faz-se necessária a elaboração de uma nova Classificação Brasileira de Ocupações/CBO(finalizada em 2002), um dos importantes suportes na descrição das ocupações e na elaboração dos itinerários de formação.

${ }^{9}$ Sobre essa questão, consultar o artigo de Maria Clara Di Pierro (2005).

10 Na mesma direção, é preciso dimensionar os recursos para o ensino profissional, analisar a proposta de constituição de novos fundos, como o FUNDEP - Fundo de desenvolvimento do ensino profissional e qualificação do trabalhador, projeto de lei n. 274, de 2003, de autoria do senador Paulo Paim, em discussão no Senado federal.

11 Como recorda Debrun (2001, p. 260), Gramsci acompanha as discussões pedagógicas que ocorrem no seio do movimento fascista italiano, nas décadas de 1920 e 1930, em torno da 'escola unitária de base'. As correntes favoráveis à escola unitária foram vencidas, prevalecendo nas reformas de Giovanni Gentili a tendência de "difundir cada vez mais as escolas profissionais especializadas, nas quais o destino do aluno e sua futura atividade são predeterminados" (Gramsci, 1972, p. 118).

\section{Referências}

BEYNON, Huw. 1999. Globalização, neoliberalismo e direitos dos trabalhadores. In: OLIVEIRA, Francisco de; PAOLI, Maria Célia (org.). Os sentidos da democracia. Petrópolis, RJ: Vozes; Brasília: Nedic, p. 265-288.

BOMENY, Helena. 2001. Os intelectuais da educação. Rio de Janeiro: Zahar.

BRANCO, Pedro P. M. 2005. Juventude e trabalho: desafios e perspectivas para as políticas públicas. In: ABRAMO, Helena W.; BRANCO, Pedro P. M. (orgs.). Retratos da juventude brasileira: análises de uma pesquisa nacional. São Paulo: Instituto da Cidadania; Ed. Perseu Abramo, p. 129-148.

CASTEL, R. 1998. As metamorfoses da questão social: uma crônica do salário. Petrópolis, RJ: Vozes.

COHN, Amélia. 1980. Previdência social e processo político no Brasil. São Paulo: Moderna.

2004. O modelo de proteção social no Brasil: qual o espaço da juventude? In: NOVAES, Regina; VANNUCHI, Paulo (orgs.). Juventude e sociedade: trabalho, educação, cultura e participa- ção. São Paulo: Ed. Perseu Abramo, p. 160-179.

CUNHA, Luiz Antônio. 1991. Educação, estado e democracia no Brasil. São Paulo: Cortez; Niterói: EDUFF; Brasília: FLACSO, 1991.

DEBRUN, Michel. 2001. Gramsci: filosofia, política e bom senso. Campinas: Ed. Unicamp.

DELGADO, Ignácio G. 2001. Previdência social e mercado no Brasil. São Paulo: LTr.

DI PIERRO, Maria Clara. 2005. Notas sobre a redefinição da identidade e das políticas públicas de educação de jovens e adultos no Brasil. Educação \& Sociedade, v. 26, n. 92, p. 1.115-1.139. Número especial.

DIEESE. 2005. Anuário dos trabalhadores 2005. São Paulo.

DUBAR, Claude. 2004. La formation professionnelle continue. Paris: La Découverte.

FIDALGO, Fernando. 1999. A formação profissional negociada: França e Brasil, anos 90. Belo Horizonte, MG: Ed. Anita Garibaldi.

FRIGOTTO, Gaudêncio. 2004a. Juventude, trabalho e educação no Brasil: perplexidades, desafios e perspectivas. In: 
NOVAES, Regina; VANNUCCHI, Paulo (orgs.). Juventude e sociedade: trabalho, educação, cultura e participação. São Paulo: Ed. Perseu Abramo, p. 180-216.

FRIGOTTO, Gaudêncio. 2004b. Sujeitos e conhecimento: os sentidos do ensino médio. In: FRIGOTTO, Gaudêncio; CIAVATTA, Maria. Ensino médio: ciência, cultura e trabalho. Brasília: Secretaria de Educação Média e Tecnológica, Ministério da Educação, p. 53-70.

; CIAVATTA, Maria. 2003. Educação básica no Brasil na década de 1990: subordinação ativa e consentida à lógica do mercado. Educação \& Sociedade, v. 24, n. 82, p. 93-132.

GRAMSCI, Antônio. 1972. Los intelectuales y la organización de la cultura. Buenos Aires: Nueva Visión.

MEC/INEP- Instituto Nacional de Estudos Pedagógicos Anísio Teixeira, Censo Educacional 2003-2004. Brasília: MEC/INEP.

IPEA. 2006. Brasil: o estado de uma nação. Brasília.

LIMA, Licínio C. 2002. Da vida, ao longo da aprendizagem. A Página da Educação, set., ano 11, n. 115, p. 21.

. 2005. Do aprender a ser à aquisição de competências para competir. Margem Esquerda, n. 5, p. 176-189.

LLAVADOR, José B. 2004. Introducción y notas críticas. In: MCLLROY, John; WESTWOOD, Sallie (orgs.). En la frontera: Raymond Williams en la educación y formación de personas adultas. Xàtiva, Diálogos-L'Ullal Edicions, p. 1-30.

MORAES, Carmen S. V.; LOPES NETO, Sebastião. 2005. Educação, formação profissional e certificação de conhecimentos: considerações sobre uma política pública de certificação profissional. Educação \& Sociedade, v. 26, n. 93, p. 1435-1469.

NEYRAT, Frédéric; PÉLAGE, Agnès. 2005. La formation continue dans le piège de l'individualisation des rapports sociaux. In: GÉLOT, Didier; NEYRAT, Frédéric; PÉLAGE, Agnès (orgs.). Pour léducation permanente: propositions pour la formation professionnelle des salariés et des chômeurs. Paris: Fundation Cpernic, p. 143-150.
PAOLI, Maria Célia. 1999. Apresentação e introdução. In: OLIVEIRA, Francisco de; PAOLI, Maria Célia (orgs.). Os sentidos da democracia. Petrópolis, RJ: Vozes; Brasília: Nedic, p. 7-23.

RUBENSON, Kjell. 2001. L'éducation des adultes en Suéde de 1967 à 2001: de l'éducation permanente à l'apprentissage tout au lon de la vie. In: TANGUY, Lucie. La formation permanente entre travail e citoyenneté. Genève: Université de Genève. (Éducation Permanente, n. 149), p.211-230.

SALLUM JR, Brasilio. 2003. Metamorfoses do Estado brasileiro no final do século XX. Revista Brasileira de Ciências Sociais, v. 18, n. 52, p. 53-54.

SOUZA SANTOS, Boaventura de. 1999. Reinventar a democracia: entre o précontratualismo e o pós-contratualismo. In: OLIVEIRA, Francisco de; PAOLI, Maria Célia (orgs.). Os sentidos da democracia. Petrópolis, RJ: Vozes; Brasília: Nedic, p. 83-129.

SANTOS, Wanderley G. dos. 1979. Cidadania e justiça. Rio de Janeiro: Campus.

SOUZA FILHO, Carlos F. de. 1999. Os direitos invisíveis. In: OLIVEIRA, Francisco de; PAOLI, Maria Célia (orgs.). Os sentidos da democracia. Petrópolis, RJ: Vozes; Brasília: Nedic, p. 307-334.

TANGUY, Lucie. 2003. Pour une production de connaissances sociologiques nécessaires à la fabrication du droit. In: MAGGI-GERMAIN, Nicole; PÉLAGE, Frédéric (dir.). Les évolutions de la formation professionnelle: regads croisés. Cahier Travail et Emploi/ Ministère des affaires sociales du travail et de la solidarité. Paris: La Documentation Française, p. 37-49.

WILLIANS, Raymond. 1981. Sociología de la cultura. México: Paidós.

WERLANG, Conrobert K. 2006. A educação profissional e tecnológica e as mudanças na legislação. In: Relatório de análise da normatização vigente no país relativa à educação profissional e tecnológica: leis, decretos, resoluções, pareceres e portarias. Brasília: Secretaria de Educação Média e Tecnológica, Ministério da Educação. (Mimeo). 
